\title{
Failure Mode and Effects Analysis Based on Fuzzy Utility Cost Estimation
}

\author{
Chensong Dong \\ Department of Mechanical Engineering \\ Curtin University of Technology \\ GPO Box U1987 \\ Perth, 6845 \\ Australia \\ Email: c.dong@curtin.edu.au
}




\title{
Failure Mode and Effects Analysis Based on Fuzzy Utility Cost Estimation
}

\author{
Abstract \\ Purpose \\ This paper aims to provide a cost effective Failure Mode and Effects Analysis tool to overcome \\ the disadvantages of the traditional FMEA that the cost due to failure is not defined.
}

\section{Approach}

The method presented in this paper is based on the Fuzzy Utility Theory. It uses utility theory and fuzzy membership functions for the assessment of severity, occurrence, and detection. The utility theory accounts for the nonlinear relationship between the cost due to failure and the ordinal ranking. The application of fuzzy membership functions better represents the team opinions. The Risk Priority Index (RPI) is developed for the prioritization of failure modes.

\section{Findings}

The advantages of the FUT-based FMEA are demonstrated through cases studies. It shows that it can take the cost due to failure into account when prioritizing failure modes.

\section{Originality/value of paper}

The FUT-based FMEA presented in this paper provides a convenient cost-effective tool for failure analysis. It improves the performance FMEA in the risk and failure analysis for product design and manufacturing/assembly process.

Key words: Failure Mode and Effects Analysis (FMEA), fuzzy, Utility Theory (UT), Risk Priority Index (RPI) 


\section{Introduction}

Failure Mode and Effects Analysis (FMEA) is a tool widely used in the automotive, aerospace, and electronics industries to identify, prioritize, and eliminate known potential failures, problems, and errors from systems under design before the product is released (Stamatis, 1995).

In FMEA, the potential failure modes and their effects are brainstormed. The severity of the effect of failure mode, the occurrence of the failure mode, and the detection of the failure mode are scaled from 1 to 10 . The risk is measured by the Risk Priority Number (RPN), which is the product of Severity, Occurrence, and Detection. A larger RPN represents a higher risk.

The disadvantages of traditional FMEA are: The three indices used for RPN calculation are ordinal scale variables. The cost due to failure cannot be defined by these ordinal numbers. Thus, the product of these three ordinal numbers is not meaningful.

Several studies on alternative FMEA approaches have been conducted. Tarum (Tarum, 2001) studied identifying and prioritizing the process part of potential problems that have the most financial impact on an operation. Based on a critical review of the method of FMEA and in particular of the risk priority number (RPN) used for ranking failure modes, Gilchrist (Gilchrist, 1993) proposed an alternative procedure, based on a simple model and using expected costs as the basis for ranking failure modes. Kmenta and Ishii (Kmenta and Ishii, 2000) developed scenario-based FMEA using expected costs. This method provides a cost based decision-making tool. However, the disadvantages are that the cost and probability are difficult to estimate without data. How to take into account experts' different opinions remains a problem.

In this paper, a Fuzzy Utility Theory based FMEA approach is presented. This approach uses utility theory and fuzzy membership functions for the assessment of severity, occurrence, 
and detection. The utility theory accounts for the nonlinear relationship between the cost due to failure and the ordinal ranking. The application of fuzzy membership functions better represents the team opinions. The Risk Priority Index (RPI) is developed for the prioritization of failure modes. The application of the method is demonstrated through two case studies.

\section{Approach}

\section{Failure Modes and Effects Assessment (FMEA)}

In the traditional FMEA, the risks are assessed by the Risk Priority Number (RPN).

$$
\mathrm{RPN}=S \times O \times D
$$

where: $S$ (severity) is an assessment of the seriousness of the effect of the potential failure mode to the next component, subsystem, system or customer if it occurs; $O$ (occurrence) is the likelihood that a specific cause/mechanism will occur; $D$ (detection) is an assessment of the ability of the current controls to detect a potential cause/mechanism or the subsequent failure mode.

Severity is estimated based on a 1 to 10 scale, e.g.

10: Very high severity ranking when a potential failure mode affects safe vehicle operation and/or involves noncompliance with government regulation without warning.

5: Vehicle/item operable but Comfort/Convenience item(s) at a reduced level of performance.

1: No discernible effect.

The evaluation of occurrence is also estimated based on a 1 to 10 scale, as shown in Table I. 


\section{Take in Table I}

Detection is estimated based on a 1 to 10 scale, e.g.

10: Absolute certainty of non-detection.

$\cdots$

5: Controls may detect.

$\cdots$

1: Controls certain to detect.

The detailed criteria for the severity, occurrence, and detection can be found in (Automotive Industry Action Group, 2001).

The RPN ranges from 1 to 1000 . Normally, an RPN greater than 200 is considered as a high risk and corrective actions should be taken.

\section{Failure Cost and Utility Theory (UT)}

Since the traditional FMEA uses ordinal numbers to rank the severity, occurrence, and detection of failure modes, it cannot provide an estimation of the cost due to failure since the cost of a failure mode ranked 10 is not always ten times of a failure mode ranked 1 . Since the ultimate goal of FMEA is to reduce the cost due to failure, the cost due to failure modes should be the objective for decision-making. The expected cost $E(C)$ due to a failure mode can be expressed as

$$
E(C)=C_{f m} p_{f m}\left(1-p_{d}\right)
$$


where $C_{f m}$ is the cost due to a failure mode, $p_{f m}$ is the probability of this failure mode and $p_{d}$ is the probability that this failure will be detected. Eqn. (2) indicates that the expected cost due to failure increases when this failure mode has severer effects, occurs more frequently, and less possibly to be detected.

Since the severity, occurrence and detection of a failure mode determines the failure cost, they can be regarded as cost drivers in the utility theory (UT). Utility theory is an attempt to infer subjective value, or utility, from choices. Utility theory can be used in both decisionmaking under risk (where the probabilities are explicitly given) and in decision-making under uncertainty (where the probabilities are not explicitly given) (Bell et al., 1988; Keeney et al., 1993). In this case, each cost driver is ranked from 1 to 10. A utility value is assigned to each level of each cost driver to reflect its influence on the expected failure cost. The higher the level, the larger the utility value.

Assigning utility values to the defined levels is a two-step process. First, the cost values for each cost driver are assigned. These values are determined by engineers based on the analysis and experience. The value of the lowest level always equals to 1 . The cost values for other levels are established according to cost magnitudes compared to that of the lowest level. For any cost driver, the cost value for level $i$ is denoted as $C_{i}, i=1 \ldots 10$.

Second, cost values are converted into utility values by dividing the cost value of the highest level for each cost driver, i.e.

$$
U_{i}=C_{i} / C_{10}
$$

After this transformation, utility values are between 0 and 1 . 
As an example, the cost values are assigned to each ranking of severity, as shown in Figure 1, which represents the non-linear relationship between the cost due to failure and the ranking of severity. Based on the cost values, the utility values are derived as shown in Figure 2.

Take in Figure 1
Take in Figure 2

The cost and utility values for detection can be derived in the same approach as severity. The evaluation of occurrence is different from that of severity and detection, since the probability of failure is given, as shown in Table I. These probability values are converted to the utility values as:

$$
U_{o}=-1 / \log p_{o}
$$

where $p_{o}$ is the probability that a failure mode occurs. After this conversion, the utility values for occurrence are between 0 and 1. An example of the utility value vs. ranking of occurrence is shown in Figure 3.

\section{Take in Figure 3}

After the utility values for severity, occurrence, and detection are derived, the Risk Priority Index (RPI) is introduced, which is defined as

$$
\mathrm{RPI}=\left(U_{s n_{s}} U_{o n_{o}} U_{d n_{d}}\right)^{1 / 3}
$$

where $n_{s}, n_{o}$, and $n_{d}$ denote the levels of severity, occurrence, and detection, respectively. The cubic root is applied to ensure that the RPI is in the same scale as individual utility values. For example, when $U_{s n_{s}}=U_{o n_{o}}=U_{d n_{d}}=0.01, \mathrm{RPI}=0.01$. The RPI ranges from 0 to 1 . 


\section{FUT-Based FMEA}

FMEA is normally a team effort in which several engineers are involved. During the early product development stage, the effects of potential failure modes are not very clear. Thus, different opinions will arise in ranking. In order to account for the differences, the Fuzzy Utility Theory (FUT) is introduced.

In FUT, the utility values are expressed by membership functions instead of real numbers (Ting et al., 1999). The introduction of FUT into FMEA is to take into account the different opinions engineers have in judging the severity, occurrence, and detection of a failure mode.

Consider severity, it is ranked from 1 to 10 . The cost value for level $i$ given by engineer $j$ is denoted as $C_{s i j}, i=1 \ldots 10, j=1 \ldots n$, where $n$ is the number of engineers.

$$
U_{s i j}=C_{s i j} / C_{s 10, j}
$$

In this paper, triangular membership functions are used. For a triangular membership function, the minimum and maximum utility values given by the engineers form the two bottom points, and the average of the utility values form the top point, i.e.

$$
\left\{\begin{array}{l}
U_{L}=\min \left(U_{j}\right) \\
U_{M}=\sum_{j=1}^{n} U_{j} / n \\
U_{U}=\max \left(U_{j}\right)
\end{array}\right.
$$

The membership grades are 0 for utility values $U_{L}$ and $U_{U}$ and 1 for utility value $U_{M}$. This is based on the assumption that among the utility values given by the engineers, the average of the values is more likely to denote the actual failure cost than the minimum value or maximum value. 
For a specific failure mode, each engineer determines the cost values $\mathrm{C}_{s i}$ for the severity and the ranking of severity. The utility values are obtained using Eqn. (6) and the membership function for severity is derived using Eqn. (7).

In the same approach, the membership functions for the occurrence and detection can be derived.

The resulting RPI is fuzzy and is expressed by the membership function instead of a general utility value as

$$
\mu(\mathrm{RPI})=\left[\mu\left(U_{s}\right) \mu\left(U_{o}\right) \mu\left(U_{d}\right)\right]^{1 / 3}
$$

where

$\mu(\mathrm{RPI})$ membership function of the Risk Priority Index;

$\mu\left(U_{s}\right)$ membership function of utility value for severity;

$\mu\left(U_{o}\right)$ membership function of utility value for occurrence;

$\mu\left(U_{d}\right)$ membership function of utility value for detection.

The membership function for the RPI needs to be defuzzified to obtain the RPI value. Two defuzzification methods are commonly used: Center of Area (COA) Method and Center of Maximum (COM) Method (Hellendoorn and Thomas, 1993). In the COA method, the center of the membership function is considered to be the expected RPI. For a triangle membership function, this is the centroid of the triangle. In the COM method, the average of the minimum utility value and the maximum utility value is considered to be the expected RPI. The results obtained using these two methods are usually very close.

The complete FUT-based FMEA process is shown in Figure 4.

\section{Take in Figure 4}




\section{Case Study}

\section{Case Study 1}

As a case study, three failure modes are evaluated by traditional FMEA and FUT-based

FMEA, respectively. When the traditional FMEA is used, the assessment of the severity, occurrence, and detection of these three failure modes and the RPN's are shown in Table II.

\section{Take in Table II}

Table II shows that the RPN's for these three failure modes are equal. Thus, it makes the prioritizing process difficult.

When the FUT-based FMEA is used, the cost due to failure can be assessed quantitatively. The cost and utility values for the severity of failure modes by five engineers are shown in Figure 5. Likewise, the cost and utility values for the detection of failure modes by five engineers are shown in Figure 6. The utility values for the occurrence are derived from Figure 3. The ranking of the severity, occurrence, and detection is shown in Table III.

\section{Take in Figure 5}

\section{Take in Figure 6}

\section{Take in Table III}


The membership functions for the severity, occurrence, and detection are derived using Eqn. (7). The membership functions for the severity, occurrence, and detection of failure mode A are shown in Figures 7-9.

\section{Take in Figure 7}

\section{Take in Figure 8}

\section{Take in Figure 9}

Based on these membership functions, the fuzzy membership functions for the RPI's of these three failure modes are derived as shown in Figure 10.

\section{Take in Figure 10}

After defuzzification, the RPI's of failure modes A-C are shown in Table IV.

\section{Take in Table IV}

This case study shows that for these three failure modes, the traditional FMEA gives the equal RPN while the FUT-based FMEA gives different RPI's. Thus, the failure modes can be better prioritized using the FUT-based FMEA. 


\section{Case Study 2}

In the second case study, there are also three failure modes A-C. When the traditional FMEA is used, the assessment of the severity, occurrence, and detection of these three failure modes is shown in Table V. The priority order is A, C, B.

\section{Take in Table $\mathrm{V}$}

When the FUT-based FMEA is used, the ranking of severity, occurrence, and detection is shown in Table VI.

\section{Take in Table VI}

If the cost values for severity and detection are assumed the same as shown in Figure 5, the membership functions for the RPI's are shown in Figure 11. After the defuzzification, the RPI values are shown in Table VII. It shows that the priority order is still A, C, B.

\section{Take in Figure 11}

\section{Take in Table VII}

In some industry, a high-ranking severity is catastrophic. The cost and utility values for severity are related with the ranking as shown in Figure 12. If the FUT-based FMEA is repeated using these cost and utility values, the membership functions for the RPI's are shown in Figure 
13. After the defuzzification, the RPI values are shown in Table VIII. It shows that the priority order changes to B, A, C.

\section{Take in Figure 12}

\section{Take in Figure 13}

\section{Take in Table VIII}

This case study shows that the traditional FMEA cannot take into account the actual cost due to failure while the influence of failure cost on the prioritization of failure modes can be reflected by the FUT-based FMEA.

\section{Conclusions}

The traditional FMEA uses RPN to prioritize failure modes. Since the three indices used for RPN calculation are ordinal scale variables, the product of these three ordinal numbers cannot define the actual cost due to failure. In this paper, a Fuzzy Utility Theory based Failure Mode and Effects Analysis is presented. This approach uses utility theory and fuzzy membership functions for the assessment of severity, occurrence, and detection. The utility theory accounts for the nonlinear relationship between the cost due to failure and the ordinal ranking. The application of fuzzy membership functions better represents the team opinions. The Risk Priority Index (RPI) is developed for the prioritization of failure modes. The two case studies conducted show that the FUT-based FMEA can take into account the actual cost due to 
failure and better prioritize failure modes. Thus, this approach provides a convenient costeffective tool for failure analysis. It improves the performance FMEA in the risk and failure analysis for product design and manufacturing/assembly process.

\section{References}

Automotive Industry Action Group (2001) QS9000 Potential Failure Mode and Effects Analysis (FMEA) Reference Manual, Third Edition.

Bell, D.E., Raiffa, H., and Tversky, A. (Eds.). (1988) Decision Making: Descriptive, Normative, and Prescriptive Interactions, Cambridge University Press, New York.

Gilchrist, W. (1993) "Modelling failure modes and effects analysis", International Journal of Quality \& Reliability Management, Vol 10 No 5, pp. 16-23.

Hellendoorn, H. and Thomas, C. (1993) "Defuzzification in fuzzy controllers", Journal of Intelligent \& Fuzzy Systems, Vol 1 No 2, pp. 109-123.

Keeney, R.L. and Raiffa, H. (1993) Decisions with Multiple Objectives: Preferences and Value Tradeoffs. Cambridge University Press, New York.

Kmenta, S. and Ishii, K. (2000) "Scenario-based FMEA: a life cycle cost perspective", Proceedings of DETC 2000, Baltimore, MD.

Stamatis, D.H. (1995) Failure Mode and Effect Analysis, ASQ Quality Press, Milwaukee, WI. Tarum, C.D. (2001) “FMERA-failure modes, effects, and (financial) risk analysis”, SAE World Congress, Detroit, MI.

Ting, P.K., Zhang, C., Wang, B., Deshmukh, A. and DuBrosky, B. (1999) "Product and process cost estimation with fuzzy multi-attribute utility theory”, Engineering Economist, Vol 44 No 4, pp. 303-331. 


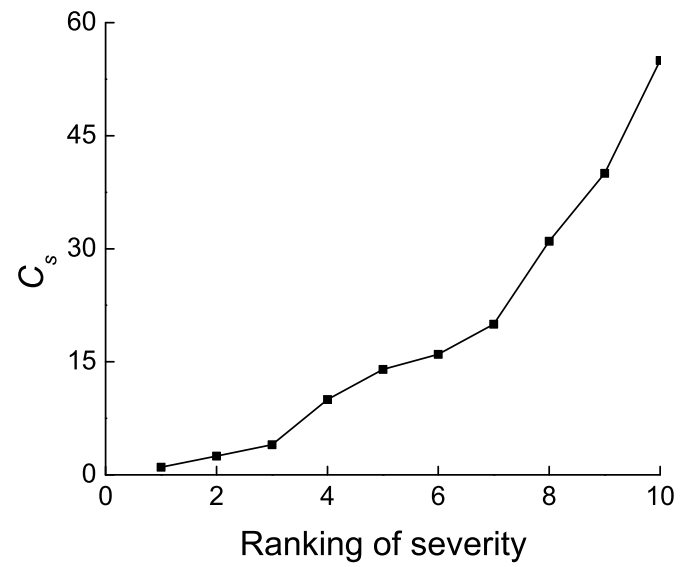

Figure 1: Cost value vs. ranking of severity

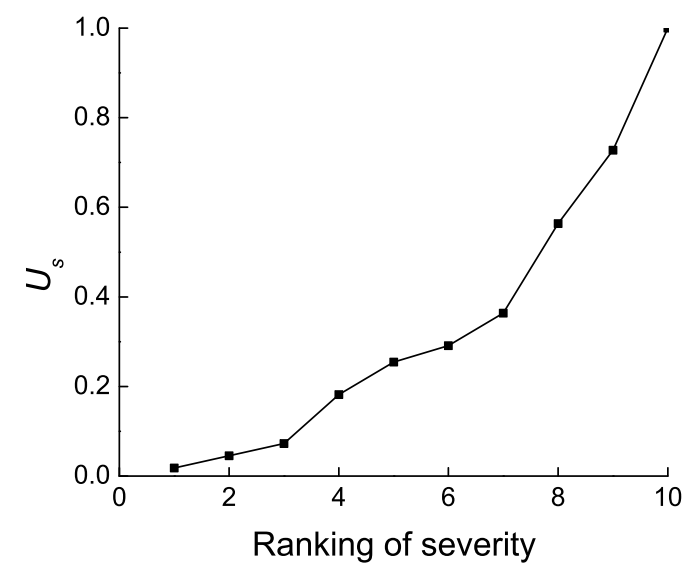

Figure 2: Utility value vs. ranking of severity

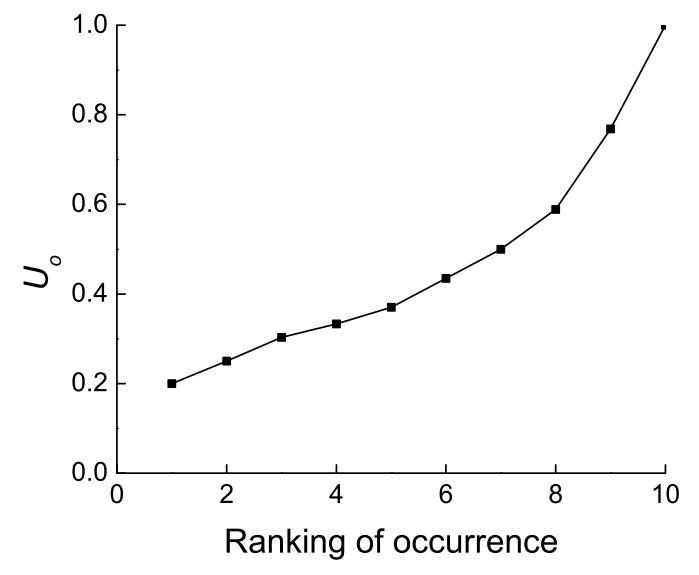

Figure 3: Utility value vs. rank of occurrence 


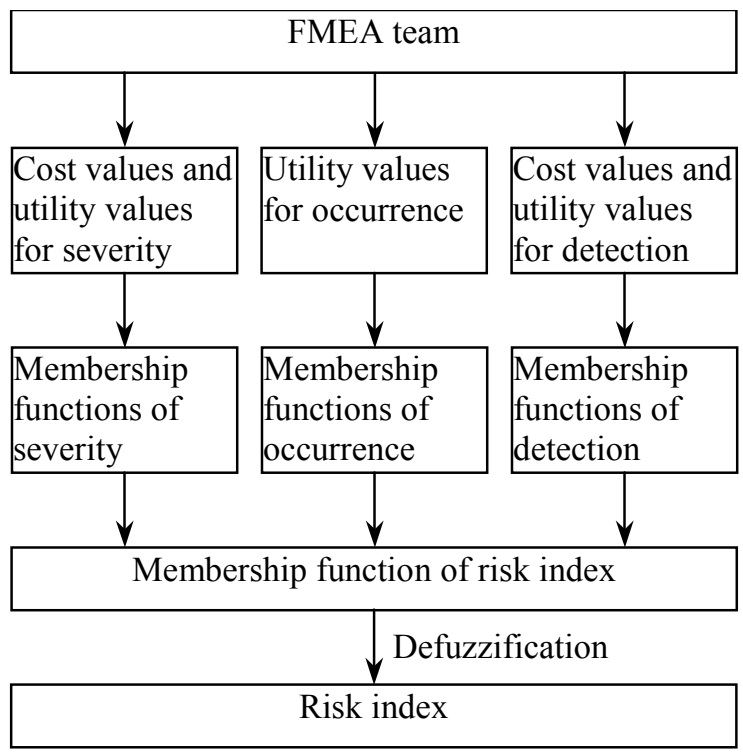

Figure 4: FUT-based FMEA
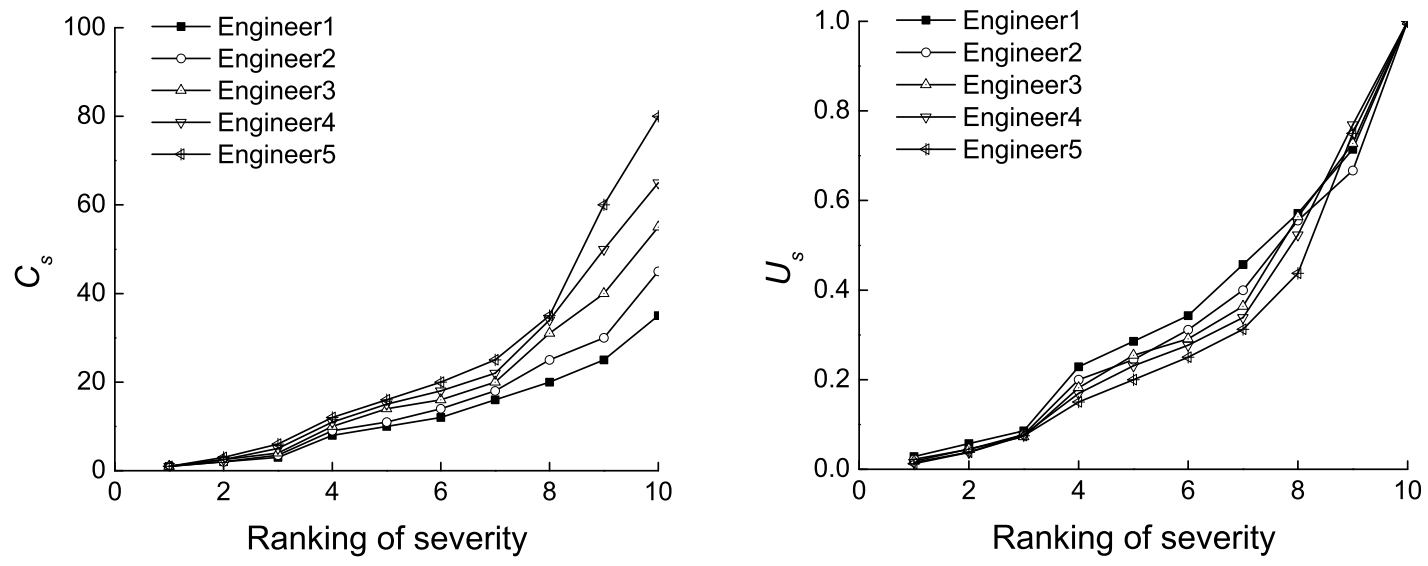

Figure 5: Cost and utility values for severity 

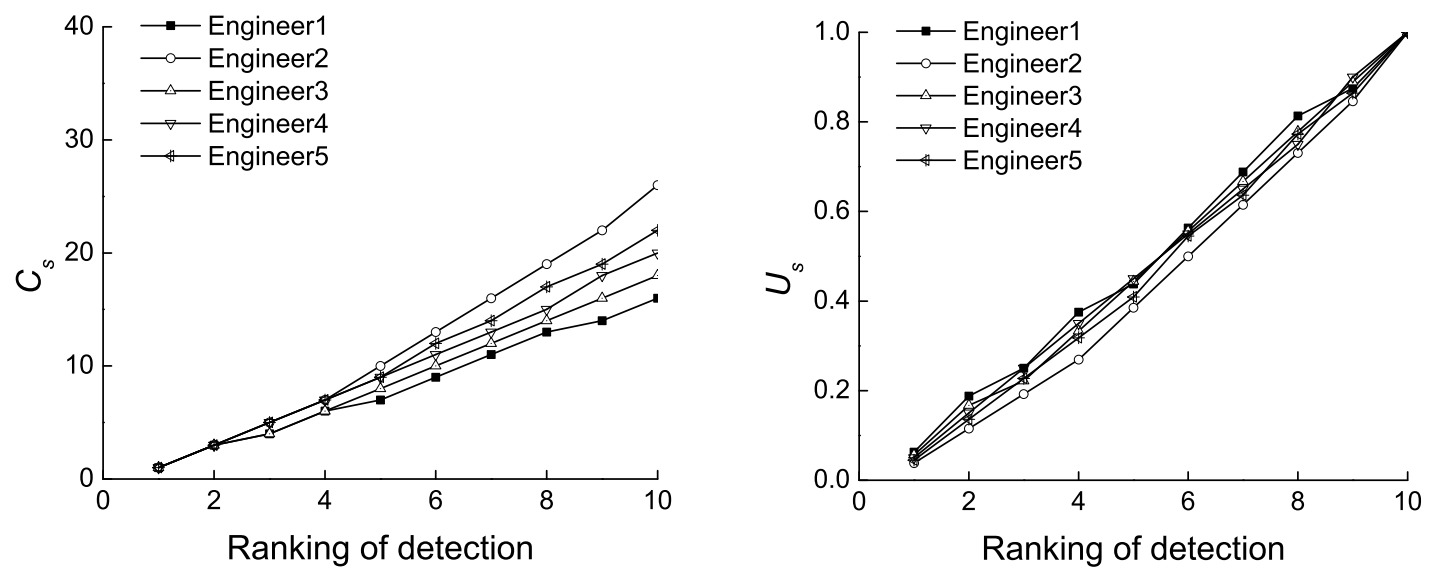

Figure 6: Cost and utility values for detection

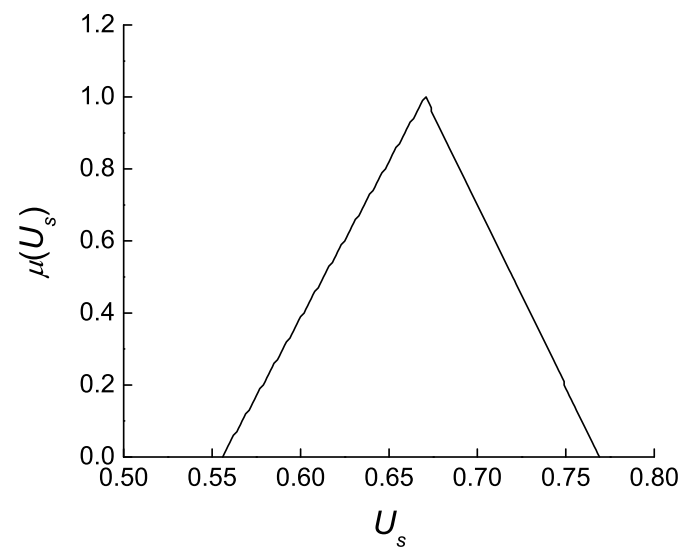

Figure 7: Membership function for severity of failure A

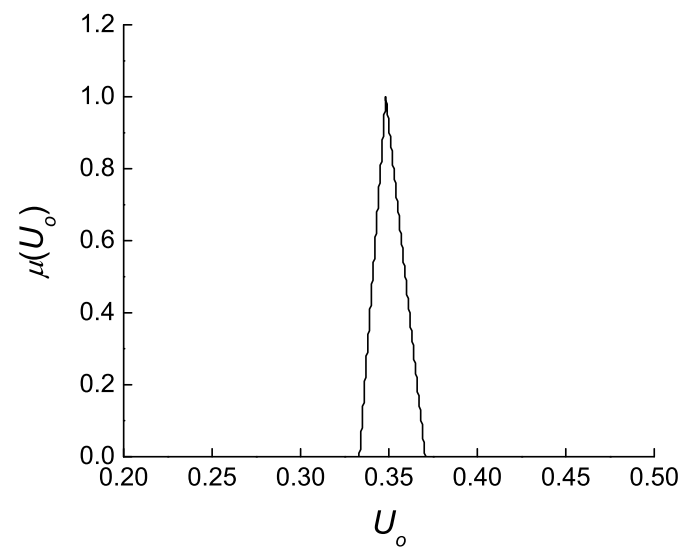


Figure 8: Membership function for occurrence of failure A

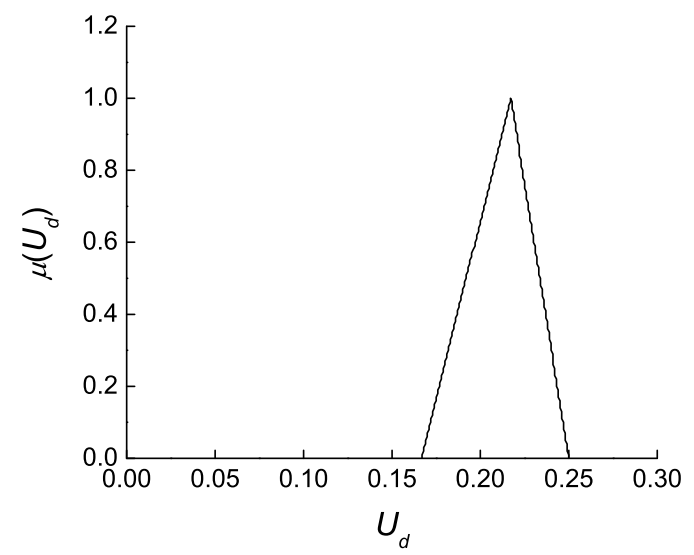

Figure 9: Membership function for detection of failure A

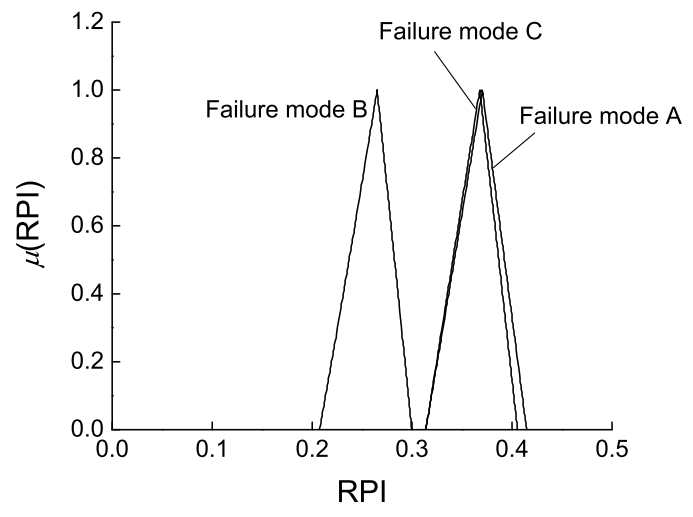

Figure 10: Fuzzy membership functions for RPI 


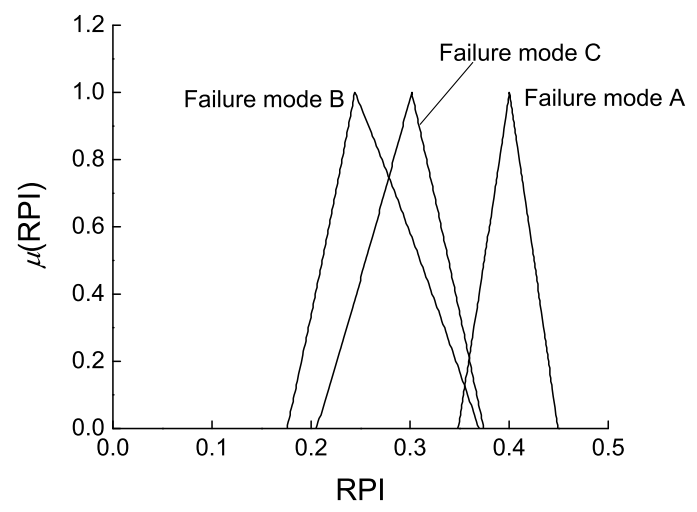

Figure 11: Fuzzy membership functions for RPI
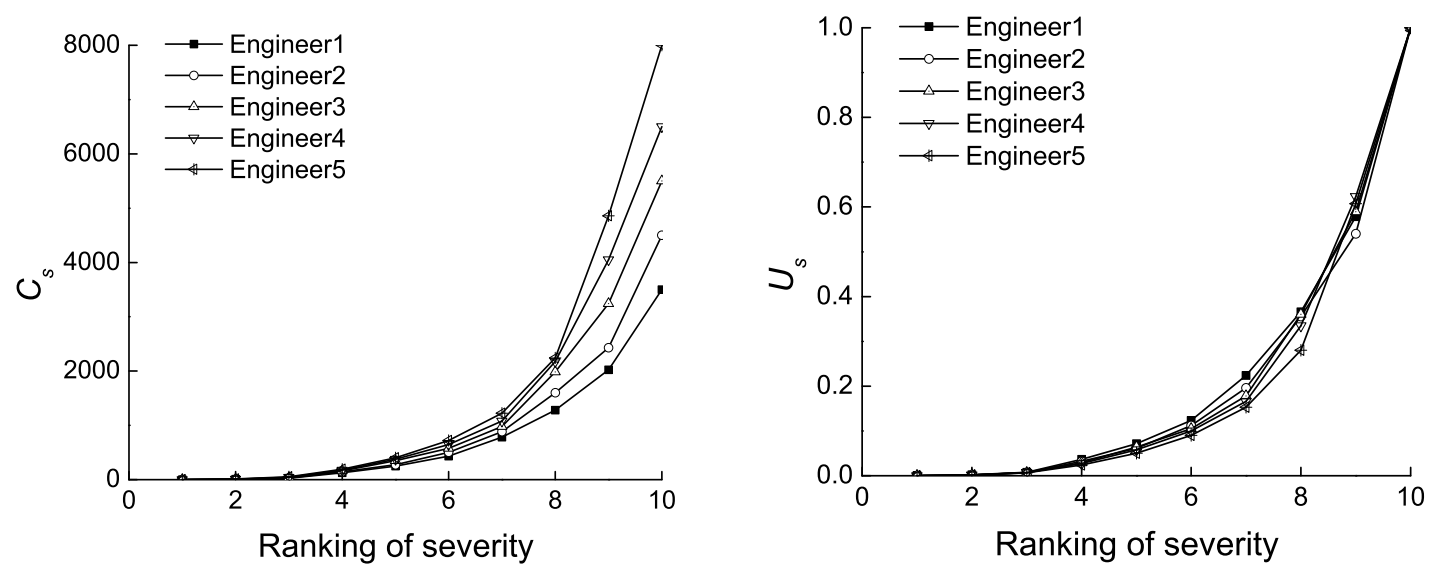

Figure 12: Cost and utility values for severity 


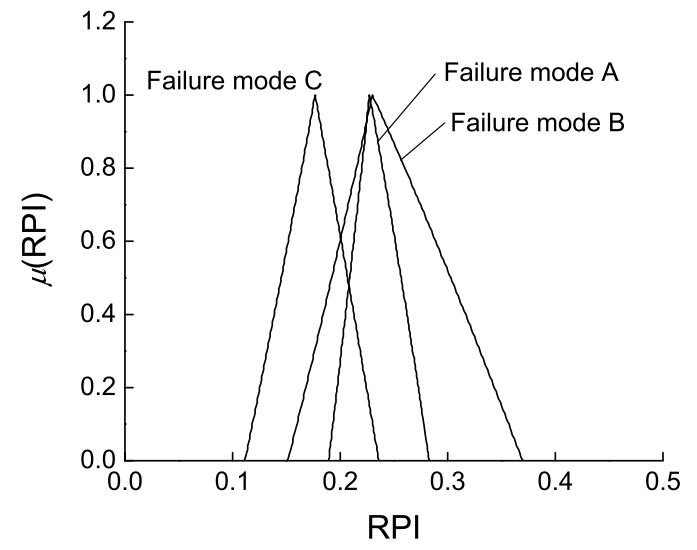

Figure 13: Fuzzy membership functions for RPI 
Table I: Ranking of occurrence

\begin{tabular}{|l|l|c|}
\hline \multicolumn{1}{|c|}{ Probability } & Likely Failure Rates & Ranking \\
\hline Very High: Persistent Failures & $\geq 100$ per thousand pieces & 10 \\
\cline { 2 - 3 } & 50 per thousand pieces & 9 \\
\hline \multirow{2}{*}{ High: Frequent Failures } & 20 per thousand pieces & 8 \\
\cline { 2 - 3 } & 10 per thousand pieces & 7 \\
\hline \multirow{2}{*}{ Moderate: Occasional Failures } & 5 per thousand pieces & 6 \\
\cline { 2 - 3 } & 2 per thousand pieces & 5 \\
\cline { 2 - 3 } & 1 per thousand pieces & 4 \\
\hline \multirow{2}{*}{ Low: Relatively Few Failures } & 0.5 per thousand pieces & 3 \\
\cline { 2 - 3 } & 0.1 per thousand pieces & 2 \\
\hline Remote: Failure is Unlikely & $\leq 0.01$ per thousand pieces & 1 \\
\hline
\end{tabular}

Table II: Traditional FMEA for three failure modes

\begin{tabular}{|l|l|l|l|l|}
\hline Failure mode & Severity & Occurrence & Detection & RPN \\
\hline A & 9 & 4 & 3 & 108 \\
\hline B & 3 & 9 & 4 & 108 \\
\hline C & 4 & 3 & 9 & 108 \\
\hline
\end{tabular}

Table III: Ranking and utility values for severity, occurrence, and detection of failure modes

\begin{tabular}{|c|c|c|c|c|c|c|c|}
\hline \multirow{2}{*}{ Failure mode } & \multirow{2}{*}{ Engineer } & \multicolumn{2}{|c|}{ Severity } & \multicolumn{2}{c|}{ Occurrence } & \multicolumn{2}{c|}{ Detection } \\
\cline { 3 - 8 } & & Ranking & $U_{s}$ & Ranking & $U_{o}$ & Ranking & $U_{d}$ \\
\hline \multirow{5}{*}{ A } & Engineer 1 & 9 & 0.714 & 4 & 0.333 & 3 & 0.250 \\
\cline { 2 - 8 } & Engineer 2 & 8 & 0.556 & 5 & 0.371 & 3 & 0.192 \\
\cline { 2 - 8 } & Engineer 3 & 8 & 0.564 & 4 & 0.333 & 2 & 0.167 \\
\cline { 2 - 8 } & Engineer 4 & 9 & 0.769 & 4 & 0.333 & 3 & 0.250 \\
\cline { 2 - 8 } & Engineer 5 & 9 & 0.750 & 5 & 0.371 & 3 & 0.227 \\
\hline \multirow{5}{*}{ B } & Engineer 1 & 3 & 0.086 & 9 & 0.769 & 4 & 0.375 \\
\cline { 2 - 8 } & Engineer 2 & 3 & 0.078 & 8 & 0.589 & 5 & 0.385 \\
\cline { 2 - 8 } & Engineer 3 & 2 & 0.045 & 8 & 0.589 & 4 & 0.333 \\
\cline { 2 - 8 } & Engineer 4 & 3 & 0.077 & 9 & 0.769 & 4 & 0.350 \\
\cline { 2 - 8 } & Engineer 5 & 3 & 0.075 & 9 & 0.769 & 5 & 0.409 \\
\hline & Engineer 1 & 4 & 0.229 & 3 & 0.303 & 9 & 0.875 \\
\cline { 2 - 8 } & Engineer 2 & 5 & 0.244 & 3 & 0.303 & 8 & 0.731 \\
\cline { 2 - 8 } & Engineer 3 & 4 & 0.182 & 2 & 0.250 & 8 & 0.778 \\
\cline { 2 - 8 } & Engineer 4 & 4 & 0.169 & 3 & 0.303 & 9 & 0.900 \\
\cline { 2 - 8 } & Engineer 5 & 5 & 0.200 & 3 & 0.303 & 9 & 0.864 \\
\hline
\end{tabular}

Table IV: Risk indices after defuzzification

\begin{tabular}{|c|c|c|}
\hline \multirow{2}{*}{ Failure mode } & \multicolumn{2}{|c|}{ Risk Priority Index (RPI) } \\
\cline { 2 - 3 } & COA & COM \\
\hline A & 0.366 & 0.364 \\
\hline B & 0.257 & 0.254 \\
\hline C & 0.362 & 0.360 \\
\hline
\end{tabular}


Table V: Traditional FMEA for three failure modes

\begin{tabular}{|c|c|c|c|c|}
\hline Failure mode & Severity & Occurrence & Detection & RPN \\
\hline A & 4 & 4 & 10 & 160 \\
\hline B & 9 & 2 & 1 & 18 \\
\hline C & 4 & 8 & 3 & 96 \\
\hline
\end{tabular}

Table VI: Ranking of severity, occurrence, and detection

\begin{tabular}{|c|c|c|c|c|c|c|c|}
\hline \multirow{2}{*}{ Failure mode } & \multirow{2}{*}{ Engineer } & \multicolumn{2}{|c|}{ Severity } & \multicolumn{2}{c|}{ Occurrence } & \multicolumn{2}{c|}{ Detection } \\
\cline { 2 - 8 } & Ranking & $U_{s}$ & Ranking & $U_{o}$ & Ranking & $U_{d}$ \\
\hline \multirow{5}{*}{ A } & Engineer 1 & 4 & 0.229 & 4 & 0.333 & 10 & 1.000 \\
\cline { 2 - 8 } & Engineer 2 & 5 & 0.244 & 5 & 0.371 & 9 & 0.846 \\
\cline { 2 - 8 } & Engineer 3 & 4 & 0.182 & 4 & 0.333 & 9 & 0.889 \\
\cline { 2 - 8 } & Engineer 4 & 4 & 0.169 & 4 & 0.333 & 10 & 1.000 \\
\cline { 2 - 8 } & Engineer 5 & 4 & 0.150 & 5 & 0.371 & 10 & 1.000 \\
\hline \multirow{5}{*}{ B } & Engineer 1 & 9 & 0.714 & 2 & 0.250 & 1 & 0.063 \\
\cline { 2 - 8 } & Engineer 2 & 9 & 0.667 & 3 & 0.303 & 1 & 0.038 \\
\cline { 2 - 8 } & Engineer 3 & 8 & 0.564 & 3 & 0.303 & 2 & 0.167 \\
\cline { 2 - 8 } & Engineer 4 & 10 & 1.000 & 2 & 0.250 & 1 & 0.050 \\
\cline { 2 - 8 } & Engineer 5 & 9 & 0.750 & 2 & 0.250 & 1 & 0.045 \\
\hline \multirow{5}{*}{ C } & Engineer 1 & 4 & 0.229 & 8 & 0.589 & 3 & 0.250 \\
\cline { 2 - 8 } & Engineer 2 & 4 & 0.200 & 7 & 0.500 & 2 & 0.115 \\
\cline { 2 - 8 } & Engineer 3 & 5 & 0.255 & 7 & 0.500 & 3 & 0.222 \\
\cline { 2 - 8 } & Engineer 4 & 5 & 0.231 & 8 & 0.589 & 4 & 0.350 \\
\cline { 2 - 8 } & Engineer 5 & 4 & 0.150 & 8 & 0.589 & 3 & 0.227 \\
\hline
\end{tabular}

Table VII: Risk indices after defuzzification

\begin{tabular}{|c|c|c|}
\hline \multirow{2}{*}{ Failure mode } & \multicolumn{2}{|c|}{ Risk Priority Index (RPI) } \\
\cline { 2 - 3 } & COA & COM \\
\hline A & 0.399 & 0.399 \\
\hline B & 0.263 & 0.273 \\
\hline C & 0.294 & 0.290 \\
\hline
\end{tabular}

Table VIII: Risk indices after defuzzification

\begin{tabular}{|c|c|c|}
\hline \multirow{2}{*}{ Failure mode } & \multicolumn{2}{|c|}{ Risk Priority Index (RPI) } \\
\cline { 2 - 3 } & COA & COM \\
\hline A & 0.233 & 0.236 \\
\hline B & 0.250 & 0.260 \\
\hline C & 0.175 & 0.174 \\
\hline
\end{tabular}

